\title{
Percutaneous closure of a left atrial appendage with relevant suture dehiscence
}

\author{
L. Kleinebrecht ${ }^{1}$ (D) $\cdot$ V. Veulemans ${ }^{1} \cdot$ A. Polzin ${ }^{1}$ M. Kelm ${ }^{1}$ T. Zeus ${ }^{1}$
}

Published online: 19 December 2016

(C) The Author(s) 2016. This article is available at SpringerLink with Open Access.

\begin{abstract}
Atrial fibrillation is a widespread disease and highly relevant as it carries an extended risk for ischaemic stroke. Surgical closure of the left atrial appendage is routinely performed during open heart surgery in patients with atrial fibrillation with the aim of thromboembolic protection. In this report we present a successful percutaneous closure of a left atrial appendage, which showed clinically relevant suture dehiscence several years after surgical closure.
\end{abstract}

Keywords Left atrial appendage closure - Suture dehiscence $\cdot$ Percutaneous device

Atrial fibrillation is linked to an increased risk of ischaemic stroke. In patients with a $\mathrm{CHA}_{2} \mathrm{DS}_{2}$-VASc score of $\geq 2$, oral anticoagulation is recommended if not contraindicated; in patients with a $\mathrm{CHA}_{2} \mathrm{DS}_{2}$-VASc score of $\geq 1$, oral anticoagulation should be considered according to the current ESC guidelines [1].

The left atrial appendage (LAA) is considered the main source of thromboembolic material. Surgical LAA closure has long been practised during open heart surgery. There is evidence, however, that up to $60 \%$ of all surgical closures are unsuccessful while suture and stapler exclusion (i. e. closing the orifice of the LAA cavity) seem to have particularly low success rates compared with surgical excision during which the LAA is actually removed [2]. In addition to that, thrombotic material could be detected in

L. Kleinebrecht

Laura.Kleinebrecht@med.uni-duesseldorf.de

1 Division of Cardiology, Pulmonary Diseases and Vascular Medicine, University Hospital Düsseldorf, Düsseldorf, Germany the LAA in up to $40 \%$ of all patients who had undergone suture or stapler exclusion [2]. However, there are no controlled clinical data concerning surgical exclusion and only two randomised controlled trials concerning percutaneous closure [3, 4]. Thus, percutaneous device closure may be considered if long-term oral anticoagulation is contraindicated, in accordance with the current ESC guidelines (Class IIb) [1]. Surgical closure of the LAA may also be considered during open heart surgery (Class IIb) [1].

There is evidence that an incomplete surgical and percutaneous exclusion of the LAA is associated with an increased risk for thromboembolic events; [2, 5] however, there is no directive how to treat patients in this constellation.

We present here the case of a 76-year-old male patient, with coronary artery disease, who underwent coronary bypass surgery in 1996. During the following years, he was diagnosed with severe mitral valve regurgitation and atrial fibrillation. Surgical valve repair was performed in 2011. Preoperatively the patient was diagnosed with liver cirrhosis due to chronic hepatitis B infection. With an elevated lifelong bleeding risk due to liver dysfunction, the LAA was surgically closed during valve surgery. The postsurgical course was uneventful and the patient was discharged on aspirin alone. In 2015, the patient suffered an ischaemic stroke. On the stroke unit a thorough search for the cause of the ischaemic event was carried out. Transoesophageal echocardiography (TEE) showed suture dehiscence of the LAA ostium with residual blood flow and smoke within the LAA (Figs. 1 and 2).

The patient had a high risk of a recurrent stroke $\left(\mathrm{CHA}_{2} \mathrm{DS}_{2}\right.$-VASc score $\left.=6\right)$. As life-long anticoagulation was risky (HAS BLED = 5), we decided to perform a percutaneous LAA closure. 


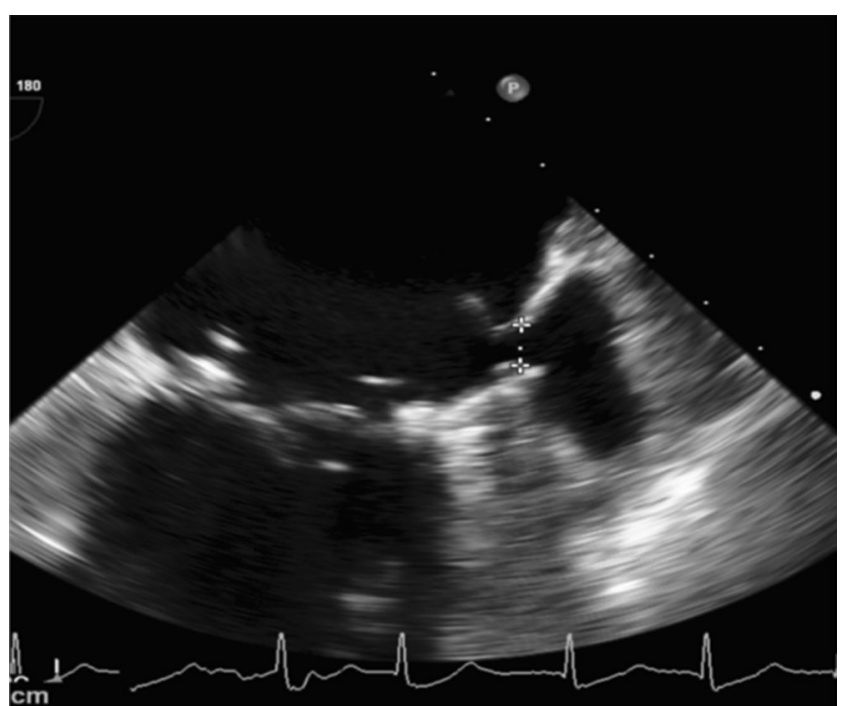

Fig. 1 Suture dehiscence (gap $6 \times 8 \mathrm{~mm}$ )

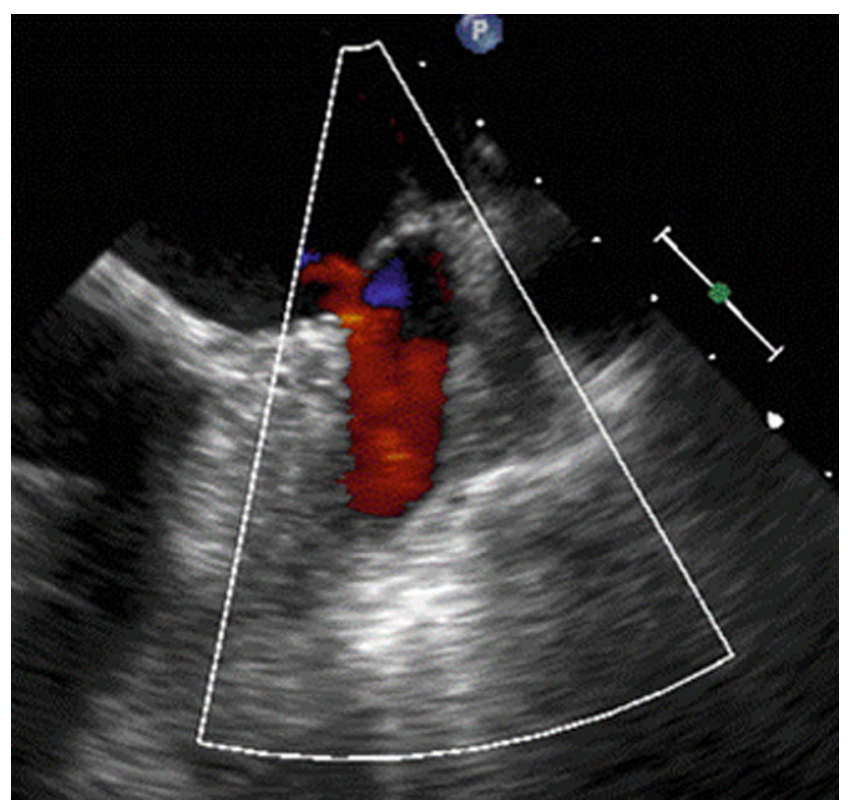

Fig. 2 Residual flow in the LAA

The patient agreed after intensive discussion of the procedural risks and alternative therapeutic options. As heparin is applied during the procedure, we waited for six weeks after the stroke to minimise the risk of secondary intracerebral bleeding. The procedure was performed under conscious sedation and with TEE guidance.

The transseptal sheath was inserted through the right femoral vein. With TEE guidance the interatrial septum was punctured in an optimal inferior and posterior position. As the entry of the LAA was too small for the advancement of a pigtail catheter into the LAA, an Amplatz Super Stiff (Boston Scientific) guidewire was positioned in the left upper pulmonary vein. The initial plan was to close the

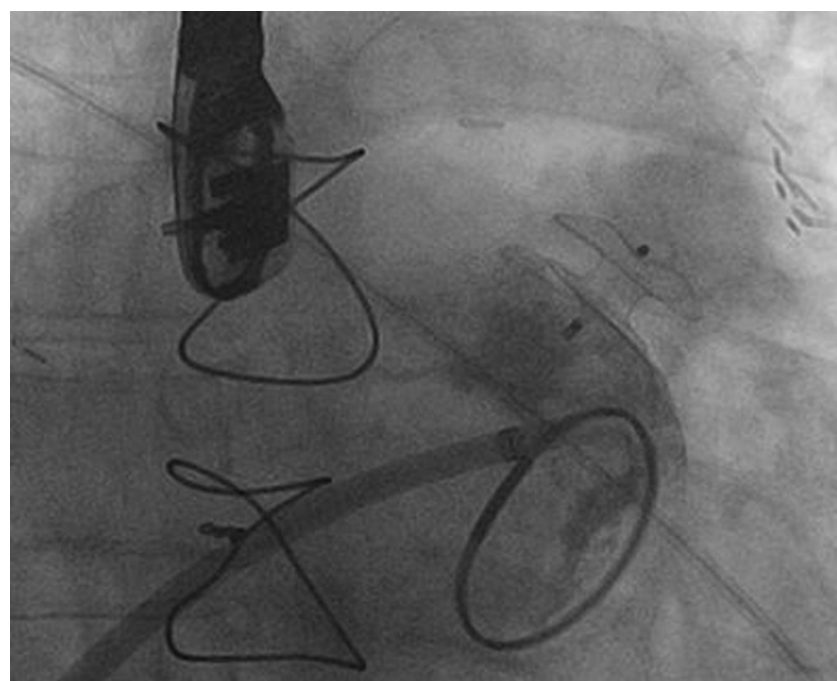

Fig. 3 ASD-Occluder placed in the LAA

LAA with a $16 \mathrm{~mm}$ AMPLATZER Amulet LAA Occluder (St. Jude Medical, SJM). Therefore a $13 \mathrm{~F} 45^{\circ} / 45^{\circ}$ double bend sheath (SJM) was introduced over the stiff wire into the left atrium. Despite good echo guidance, the sheath could not be advanced safely into the LAA. We thought that this was mainly due to the relatively large sheath diameter in correlation to the small, residual LAA ostium and the double bend curve. Therefore we changed to a 9 French standard single bend sheath $\left(45^{\circ}, \mathrm{SJM}\right)$. The $9 \mathrm{~F}$ sheath could be advanced effortlessly into the LAA. As the oval shaped residual LAA ostium measured $6 \times 8 \mathrm{~mm}$, an $8 \mathrm{~mm}$ AMPLATZER Septal Occluder (SJM) was chosen. A smaller one was considered to achieve insufficient anchoring. A bigger one was considered to increase the risk of erosion due to the $18 \mathrm{~mm}$ distal disc diameter, which would be placed within the LAA. The waist of the $8 \mathrm{~mm}$ ASD occluder could be positioned within the LAA ostium and the proximal disc covered the LAA ostium completely. Neighbouring structures were not affected. The occluder was released and TEE showed a good final result (Fig. 3).

The patient was transferred to the intermediate care unit, where he spent $24 \mathrm{~h}$ free from events. We recommended six months of dual antiplatelet therapy (aspirin and clopidogrel) followed by life-long therapy with aspirin only. Follow-up of 13 months until now has been uneventful (Fig. 4).

\section{Summary}

Surgical atrial appendage occlusion is often performed during open heart surgery. Insufficient occlusion leads to an elevated risk of thromboembolism. Our patient suffered a stroke several years after a surgically occluded LAA. Transoesophageal echocardiography showed a residual en- 


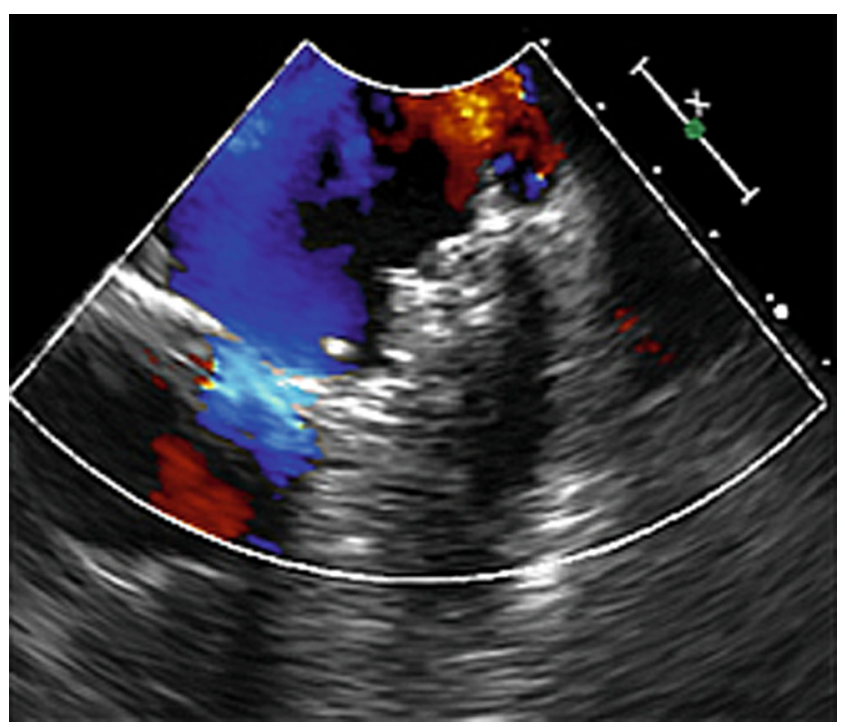

Fig. 4 TEE performed three months after the procedure, showing no flow in the LAA

try to the LAA. Percutaneous closure could be performed with an atrial septal defect (ASD) occluder. Post-interventional imaging showed that the LAA ostium was perfectly sealed.

With regards to the possible impact of ischaemic strokes it seems sensible to perform TEE controls after surgical and percutaneous LAA closure. There is little evidence on when to perform these tests. Concerning percutaneous device closure, TEE is routinely performed three months after the procedure in our clinic. As suture dehiscence in surgically closed LAA might occur later on, it may be necessary to examine these patients even years after the surgery.

Funding Master Research Agreement with Philips

Conflict of interest L. Kleinebrecht, V. Veulemans, A. Polzin, M. Kelm and T. Zeus declare that they have no competing interests.

Open Access This article is distributed under the terms of the Creative Commons Attribution 4.0 International License (http:// creativecommons.org/licenses/by/4.0/), which permits unrestricted use, distribution, and reproduction in any medium, provided you give appropriate credit to the original author(s) and the source, provide a link to the Creative Commons license, and indicate if changes were made.

\section{References}

1. Camm AJ, Lip GY, De Caterina R, et al. 2012 focused update of the ESC Guidelines for the management of atrial fibrillation: an update of the 2010 ESC Guidelines for the management of atrial fibrillation - developed with the special contribution of the European Heart Rhythm Association. Europace. 2012;14:1385-413.

2. Kanderian AS, Gillinov AM, Pettersson GB, et al. Success of surgical left atrial appendage closure: assessment by transesophageal echocardiography. J Am Coll Cardiol. 2008;52:924-9.

3. Reddy VY, Sievert H, Halperin J, et al. Percutaneous left atrial appendage closure vs warfarin for atrial fibrillation: a randomized clinical trial. JAMA. 2014;312:1988-98.

4. Holmes DR Jr., Kar S, Price MJ, et al. Prospective randomized evaluation of the watchman left atrial appendage closure device in patients with atrial fibrillation versus long-term warfarin therapy: the PREVAIL trial. J Am Coll Cardiol. 2014;64:1-12.

5. Garcia-Fernandez MA, Perez-David E, Quiles J, et al. Role of left atrial appendage obliteration in stroke reduction in patients with mitral valve prosthesis: a transesophageal echocardiographic study. J Am Coll Cardiol. 2003;42:1253-8. 